\title{
A batalha entre a liberdade e a tirania: Revolução Cubana, guerra de guerrilhas e o desenvolvimento da Doutrina de Contrainsurgência norte-americana nos anos 1960
}

Pâmela de Almeida Resende ${ }^{1}$

Resumo: O objetivo central deste artigo é analisar a construção e o desenvolvimento das políticas produzidas no âmbito do governo dos Estados Unidos para a América Latina, sobretudo a partir da década de 1960. Tal escolha justifica-se pelo interesse em compreender as ações desenvolvidas para combater os movimentos guerrilheiros que se faziam atuantes nos países latino-americanos, além da influência e do impacto da Revolução Cubana nesse processo. A criação de programas de ajuda externa, com destaque para a Aliança para o Progresso, aliada ao desenvolvimento da Doutrina de Contrainsurgência, ambas no governo de John F. Kennedy, nos parece fundamental para a compreensão das estratégias adotadas pelos Estados Unidos na sua política de contenção do avanço comunista na região.

Palavras-chave: Estados Unidos; América Latina; Revolução Cubana; Guerra de guerrilhas; Contrainsurgência

\section{The battle between freedom and tyranny: Cuban Revolution, guerrilla warfare and the development of the American Counterinsurgency Doctrine in the 1960s}

\begin{abstract}
The main objective of this article is to analyze the construction and development of policies produced under the United States government for Latin America, especially from the decade of 1960 . This choice is justified by the interest in understanding the actions developed to combat the guerrilla movements that were active in Latin American countries, in addition to the influence of the Cuban revolution in this process. The creation of external aid programs, highlighting the Alliance for Progress, coupled

\footnotetext{
${ }^{1}$ Doutora em História Social pela Universidade de São Paulo (USP) e pesquisadora do Grupo de Estudos sobre Guerra Fria (CNPq/USP). Este artigo é resultado de algumas reflexões também publicadas na minha tese de doutorado, intitulada "Ser um embaixador não é um mar de rosas": o sequestro do embaixador Charles Burke Elbrick no Brasil em 1969, financiada pela CAPES. E-mail: pamelaresende@ yahoo.com.br.
} 
with the development of the counterinsurgency doctrine both in the government of John F. Kennedy, seems to us to be instrumental in understanding the strategies adopted by the United States in its policy of containment of communist advancement in the region.

Keywords: United States; Latin America; Cuban revolution; Guerrilla warfare; Counterinsurgency.

Artigo recebido em: 30/06/2020

Artigo aprovado para publicação em: 28/09/2020

\section{Introdução}

Terrorismo, guerra de guerrilha, insurgência e subversão, apesar de não possuírem o mesmo significado, conformaram um vocabulário comum para definir indivíduos que fizeram uso da violência como prática política e alternativa à via pacífica no pós-Segunda Guerra Mundial. A contrainsurgência, por sua vez, seria definida pela constituição de ações políticas, militares, psicológicas e cívicas para a dissolução de movimentos insurgentes na disputa por corações e mentes.

Nesse cenário, a consolidação da Doutrina de Contrainsurgência como política de Estado norte-americana, nos anos 1960, guarda estreita relação com o início da Guerra Fria, o "sentido de missão" (AZEVEDO, 1998) e a contenção dos ideais comunistas em um mundo cada vez mais polarizado ideologicamente. Com uma retórica que colocava Estados Unidos e União Soviética em pólos opostos - democracia versus totalitarismo -, o discurso do presidente dos Estados Unidos, Harry Truman, dirigido ao Congresso norteamericano em 1947 delimitava claramente tal posição:

No atual momento da história mundial cada nação deve escolher entre os modos de vida opostos. A escolha não é frequentemente livre. Um modo de vida baseia-se na vontade da maioria e se caracteriza por instituições livres, governo representativo com eleições livres, garantias de liberdade individual, liberdade de expressão e de religião, e pela supressão das formas de opressão política. Uma outra forma de vida baseia-se na vontade de uma minoria imposta à força à maioria. Ela se apoia no terror e na opressão, no controle da imprensa e do rádio, em eleições manipuladas e na supressão das liberdades individuais. Acredito que a política dos Estados Unidos deve ser de apoiar os povos livres que estão resistindo a subjugação por minorias armadas ou por 
pressões exteriores. Acredito que nossa ajuda deve ser primeiramente através da estabilidade econômica e da ordenação do processo político. ${ }^{2}$

Para a urgente e necessária contenção ${ }^{3}$ do expansionismo soviético e das ideias comunistas, o governo norte-americano apoiou-se no anticomunismo como componente fundamental do seu projeto intervencionista, sobretudo nos países do Terceiro Mundo. Progressivamente, uma série de agências, acordos e tratados foram criados nos bastidores do governo norte-americano. Ainda em 1947, Truman assinou o National Security Act (NSA), que reunia o Departamento da Marinha e o Departamento de Guerra no recémcriado Departamento de Defesa com o objetivo de fortalecer as instituições militares. Destaca-se, ainda, a criação do National Security Council (CSN) e da Central Intelligence Agency (CIA), que atuou não apenas como uma agência de inteligência, mas diretamente em operações secretas e no financiamento de intelectuais de centro e esquerda (CANCELLI, 2017; SAUNDERS, 2008). Além disso, outra estratégia fundamental foi a implementação de escolas de treinamento e formação militar. Como apontou Samantha Viz Quadrat:

"a divulgação da Doutrina de Segurança Nacional e a crença na necessidade de combater o comunismo na América Latina acabou por aproximar os oficiais e as próprias instituições - que superaram disputas históricas e territoriais diante da necessidade de cooperação entre os países" (QUADRAT, 2012, p. 33).

Nesse cenário de articulação interamericana contra a "subversão" e de aprofundamento das disputas por zonas de influência entre Estados Unidos e União Soviética, a Escola das Américas, no Panamá, criada em 1946 no interior do Departamento de Defesa, ganha proeminência na preparação de oficiais latino-

\footnotetext{
${ }^{2}$ TRUMAN, Harry. The Truman Doctrine. Disponível em: https://www.americanrhetoric.com/speeches/PDFFiles/Harry\%20Truman\%20\%20Truman\%20Doctrine.pdf Acesso em 02/04/2020.

${ }^{3}$ George Kennan, diplomata e profundo conhecedor da política soviética, é tido como um dos principais articuladores da Doutrina de Contenção, que visava impedir o expansionismo da URSS nos anos iniciais da Guerra Fria. Em fevereiro de 1946, Kennan teria enviado, a pedido do Departamento de Estado, aquele que ficou conhecido como o "Longo telegrama", no qual argumentava que o expansionismo soviético precisava ser contido em regiões consideradas estratégicas para os Estados Unidos.
} 
americanos à medida que começam a pulular em diversas partes do mundo focos guerrilheiros e movimentos de libertação nacional.

Para o caso que interessa a este artigo, a Revolução Cubana, a disseminação das ideias dos chamados "teóricos da revolução" e a noção de que a única saída possível para os povos do Terceiro Mundo seria a luta armada encontraram eco nos diversos agrupamentos guerrilheiros, que cada vez mais levantavam a bandeira da violência como legítima prática política. Além disso, havia uma forte crítica à interferência dos Estados Unidos nos assuntos internos dos países da América Latina.

No entanto, importa observar que, apesar de reconhecer a centralidade da experiência cubana em todo esse processo e, sobretudo, na construção da Doutrina de Contrainsurgência durante o governo de John F. Kennedy, a partir de 1961, não é possível supor que o continente latino-americano estivesse fora da órbita do governo norteamericano antes de 1959. Como vimos acima, uma série de iniciativas foram estabelecidas desde pelo menos o final da Segunda Guerra Mundial, além do papel fundamental dos Estados Unidos no golpe de 1954 na Guatemala, que depôs o presidente Jacob Arbenz. Conforme apontou Ana Carolina Reginatto:

\footnotetext{
"as estratégias políticas e militares para derrubar um governo eleito democraticamente, assim como o financiamento posterior para a formação de aparatos repressivos utilizados na Guatemala, serviram de exemplo para o dramático avanço do arbítrio pelo continente" (REGINATTO, 2016, p. 95).
}

O mundo que emergiu dos escombros da Segunda Guerra Mundial alterou de modo significativo a agenda política internacional. Além da difícil tarefa de reconstrução da Europa, a questão dos apátridas e seu não-lugar no mundo, assistiu-se à formação de uma série de novos Estados-nações com identidades e reivindicações próprias. Nas últimas décadas, assistimos a uma renovação dos estudos históricos a partir do redimensionamento da compreensão das relações interamericanas na segunda metade do século XX. A disponibilização de novas fontes documentais e aportes metodológicos 
trazidos pela história global e transnacional tem sido fundamental para a revisão da historiografia tradicional sobre a Guerra Fria, ainda muito centrada na ideia de um conflito bipolar entre Estados Unidos e União Soviética.

Nesse sentido, algumas correntes têm buscado enfatizar que a análise daquele período sob a ótica da dimensão bipolar acabaria por escamotear as tensões e disputas por hegemonia no âmbito regional (WESTAD, 2007; WESTAD, 2000; MUNHOZ, 2017; CANCELLI, 2017). No caso específico da América Latina, alguns estudos (JOSEPH \& SPENSER, 2008; HARMER, 2013; JOSEPH, 2019; BOOTH, 2020) procuram discutir o papel desse continente no contexto da Guerra Fria, levando em consideração o protagonismo e não a recepção passiva dos projetos e políticas das superpotências -, as especificidades, e a complexa rede de circulação de ideias e atores estatais e não-estatais. Com isso, esses sujeitos passam a ser protagonistas de sua própria história, além de ganhar relevância aspectos culturais e sociais antes obliterados. Na esteira dessas reflexões, este artigo pretende contribuir com as discussões propostas nessas novas abordagens, recolocando não apenas o papel da Revolução Cubana, mas principalmente descortinando alguns aspectos da política externa norte-americana e sua base ideológica de sustentação.

\section{“Um, dois, três, muitos Vietnãs": a Revolução Cubana em debate}

No livro The Darker Nations: a people's history of the Third World, o autor Vijay Prashad (PRASHAD, 2007) afirma que, mais que um lugar, o Terceiro Mundo é um projeto. A Conferência de Bandung, ocorrida em 1955 na Indonésia, moldaria esse projeto tendo no horizonte a soberania nacional e o desenvolvimento econômico dos países do Terceiro Mundo. Nesse cenário, intensificou-se a narrativa da urgência da libertação econômica, política e cultural dos países do Terceiro Mundo, a partir da possibilidade de se imaginar um novo mundo. A ação direta aparece, cada vez mais, como alternativa à via pacífica e, igualmente, como ruptura e desencantamento com o modo de fazer política. 
Naquele momento, muitos intelectuais se debruçaram na tentativa de explicar o papel e a glorificação da violência que esses grupos projetavam para a História, a partir da noção da utilização da violência como meio legítimo de transformação social e prática revolucionária. No prefácio escrito por Jean Paul Sartre para o livro Os condenados da terra (FANON, 2005), de autoria do médico martinicano Frantz Fanon, ele relaciona a centralidade do uso da violência não apenas como importante instrumento de libertação, mas como resposta à desumanização gerada pelo projeto colonizador. Publicado no ano de 1961, esse livro influenciaria não apenas Sartre, mas uma série de intelectuais que também se debruçaram sobre o assunto.

A filósofa Hannah Arendt, por exemplo, tratará dessa questão na obra $D a$ violência (ARENDT, 2010), escrita entre os anos 1968 e 1969, na qual problematiza a identificação que segmentos da esquerda do pós-guerra, especialmente a Nova Esquerda ${ }^{4}$ e o movimento estudantil, estabeleceram da violência como prática política. Essa valorização da violência acompanhada da necessidade de justificá-la teoricamente seria, segundo Arendt, uma demonstração de como o uso da violência estaria legitimado não apenas em casos extremos, como o de invasão de territórios, mas funcionaria como um dispositivo constituinte da identidade desses grupos. Porém, na visão arendtiana, a ideia de uma "violência justa" nega o espaço da coisa pública na medida em que promove um esvaziamento da política e a própria negação da diversidade e da possibilidade de diálogo. Além disso, Arendt questiona a identificação, um tanto enviesada, que esses movimentos estabeleceram entre a violência e a ação política ao pensamento marxista:

\footnotetext{
Naturalmente Marx conhecia o papel da violência na história, mas para ele era um papel secundário; o que traria o fim da velha sociedade não era a violência, mas as contradições inerentes a esta sociedade. O surgimento de uma nova sociedade seria precedido, mas não causado por violentas insurreições as quais ele comparou às dores do parto, que precedem, mas obviamente não causam o nascimento orgânico. (ARENDT, 2010, p. 100)
}

\footnotetext{
${ }^{4}$ A chamada Nova Esquerda abarca não apenas a New Left norte-americana, mas movimentos no mundo todo, como a extrema-esquerda na Europa, Argélia, América Latina, etc.
} 
Respeitadas as devidas particularidades, temos a configuração de um ethos comum para as esquerdas que emergiram, principalmente a partir da década de 1960: a radicalidade política. Também na América Latina parte da esquerda enalteceu a violência como alternativa à via pacífica e às formas tradicionais de ação política. ${ }^{5}$ Os anseios libertários que varreram boa parte dos países do Terceiro Mundo estavam calcados na crença de que era preciso romper com a burocratização dos partidos tradicionais de esquerda e com a influência da URSS. Havia uma crescente disputa entre os grupos considerados reformistas e aqueles que apostavam na instauração do socialismo por meio da luta armada. Essas duas correntes que apregoavam entre modos distintos de atuação ficariam cada vez mais evidentes, e não seria exagerado afirmar o papel decisivo que teve a Revolução Cubana nessa disputa.

O ano de 1959 pode ser considerado o turning point para a esquerda radical, sobretudo nos países da América Latina. As profundas transformações econômicas, sociais e políticas que se seguiram à Revolução Cubana ainda hoje reverberam entre estudiosos do assunto e mesmo entre a opinião pública. De acordo com Carlos Alberto Barão,

\begin{abstract}
A Revolução Cubana marcou profundamente a esquerda latino-americana e, em certa medida, também a esquerda mundial, não somente por demonstrar que era possível vencer o imperialismo norte-americano em seu próprio 'quintal', mas também por ter rompido os padrões clássicos de luta seguidos pela esquerda marxista-leninista da época, sempre centrados no partido revolucionário. $\mathrm{O}$ poder não foi alcançado por meio de um partido de vanguarda, como no modelo russo, nem basicamente como resultado de uma vitória militar camponesa, como no modelo chinês.(BARÃO, 2003, p. 263)
\end{abstract}

\footnotetext{
${ }^{5}$ Segundo Izabel Priscila Pimentel da Silva, "As teses terceiro-mundistas e a noção de violência justa também repercutiram em significativos setores da Igreja Católica na América Latina. A partir de mudanças institucionais introduzidas pelo Concílio Vaticano II, setores progressistas da Igreja aproximaram-se dos projetos de transformações sociais defendidos pelas esquerdas radicais latino-americanas". SILVA, Izabel Priscila Pimentel da. "Por ti, América": Luta Armada, Internacionalismo e Latino-Americanismo na trajetória da Junta de Coordinación Revolucionaria. Tese de Doutorado. Niterói: UFF, 2016, p. 54.
} 
Com o sucesso obtido pela experiência cubana, temos a publicação extensiva de livros e manuais que buscavam compreender aquela experiência, visando ao seu alcance para a luta dos povos dos demais países periféricos, com destaque para o continente latino-americano. A esquerda revolucionária que emergiu durante a década de 1960 foi influenciada diretamente pelos escritos dos chamados "teóricos da revolução".

Um ano após a derrocada do ditador Fulgêncio Batista e a entrada vitoriosa dos guerrilheiros em Havana, Che Guevara surgiu como uma das principais referências entre os teóricos da revolução ao sistematizar as condições materiais para a transição ao socialismo, a luta revolucionária, suas características e abordagens. Em 1960 era lançado A Guerra de guerrilhas (GUEVARA, 1982), a primeira análise de Guevara sobre os rumos da estratégia revolucionária latino-americana. ${ }^{6}$ De acordo com ele, a Revolução Cubana ofereceu três contribuições fundamentais para o desenvolvimento da luta revolucionária na América ${ }^{7}$ :

1) - As forças populares podem ganhar uma guerra contra o exército;

2) - Não é preciso esperar sempre que todas as condições se reúnam para fazer a revolução; o núcleo insurrecional pode criá-las;

3) - $\mathrm{Na}$ América subdesenvolvida, o terreno da luta armada deve, fundamentalmente, ser o campo". (GUEVARA, 1982, p. 13)

Ali encontravam-se os elementos centrais da teoria da guerra de guerrilhas. A luta armada era encarada como uma luta de massas com o apoio e a formação de um exército popular que tornaria possível a vitória. Para Guevara, as condições para a revolução podem e devem ser criadas, em uma clara crítica à burocratização dos partidos tradicionais, suas alianças com as burguesias nacionais e os dogmas stalinistas. ${ }^{8}$ Guevara

\footnotetext{
${ }^{6}$ Além do conhecido A Guerra de Guerrilhas, Che Guevara publicou outros escritos ao longo dos anos 1960 que influenciaram de modo decisivo os agrupamentos guerrilheiros na América Latina. Destacamos Passagens da guerra revolucionária (1963).

${ }^{7}$ Che Guevara reafirmaria seus pressupostos em outro texto, lançado em 1963, denominado Guerra de guerrilhas: um método.

${ }^{8}$ A morte de Stálin, em 1953, e a publicação do relatório denunciando seus crimes, por Nikita Kruschev, representou um marco para parte do movimento comunista internacional. A partir de então, a União Soviética inaugura uma nova fase política de abertura do diálogo com os países capitalistas.
} 
defendia, ainda, que o campo era o local mais propício para o desenvolvimento e a instalação dos movimentos guerrilheiros, já que o acesso das formas repressivas era mais difícil que nas cidades. Esse ponto é fundamental porque traz à tona a chamada teoria do foco. Segundo Guevara, o "foco" se tornaria viável a partir da ação de um pequeno grupo de guerrilheiros localizados preferencialmente em alguma região rural. Com a formação de colunas guerrilheiras, a próxima etapa seria conquistar simpatizantes, sobretudo entre os camponeses.

A consolidação dessas ideias ocorreu em Janeiro de 1966 durante a I Conferência Tricontinental de Solidariedade dos Povos da Ásia, África e América Latina, realizada na cidade de Havana. ${ }^{9}$ Nessa ocasião, Guevara já estava atuando clandestinamente na Bolívia, mas mesmo assim mandou uma mensagem ressaltando a importância dos países latino-americanos para a luta revolucionária:

\begin{abstract}
A América, continente esquecido pelas últimas lutas políticas de libertação, que começa a se fazer ouvir por intermédio da Tricontinental, por meio da voz da vanguarda de seus povos, que é a Revolução Cubana, terá uma tarefa de muito maior relevância: a da criação do segundo ou terceiro Vietnã ou do segundo e terceiro Vietnã do mundo. Definitivamente, deve-se levar em conta que o imperialismo é um sistema mundial, última etapa do capitalismo, e que é preciso batê-lo em um grande confronto mundial. A finalidade estratégica dessa luta deve ser a destruição do imperialismo (...). O elemento fundamental dessa finalidade estratégica será, portanto, a libertação real dos povos; libertação que ocorrerá pela luta armada, na maioria dos casos, e que terá, na América, quase inexoravelmente, a propriedade de se transformar em uma Revolução Socialista. (GUEVARA, 2016, p. 305)
\end{abstract}

A influência e recepção da mensagem enviada por Che Guevara foram significativas entre os grupos guerrilheiros ao reforçarem o protagonismo da América Latina naquele processo. A ideia de que a revolução e a libertação dos povos só teria sucesso via luta armada é reiteradamente enfatizada. Durante a Tricontinental, foi criada a OLAS - Organização Latino-Americana de Solidariedade cuja função era coordenar o

\footnotetext{
${ }^{9} \mathrm{~A}$ Tricontinental surgiu como um catalisador dos movimentos anti-imperialistas em regiões como África, Ásia e América Latina.
} 
processo revolucionário, principalmente por meio do financiamento e treinamento de quadros guerrilheiros. ${ }^{10}$

Na primeira conferência da OLAS, no ano seguinte, 1967, participaram diversos grupos revolucionários e as posições tomadas naquela ocasião demonstram a independência da posição cubana em política internacional com relação à China e ao bloco socialista liderado pela URSS, na medida em que descartava o papel progressista das burguesias nacionais defendida por ambos (BARÃO, 2003, p. 269). Naquela ocasião, a OLAS reafirmou, ainda, a crítica à ingerência dos Estados Unidos nos países do continente, tendo em vista o pressuposto de que a revolução deveria ser, antes de tudo, anti-imperialista, além da opção pela luta armada como instrumento de emancipação da América Latina. ${ }^{11}$ Para Jean Rodrigues Sales (SALES, 2005, p. 94), a realização da Tricontinental, em 1966, e a criação da OLAS, no ano seguinte, são as partes mais visíveis do esforço da política cubana em se tornar um centro revolucionário no continente americano.

A publicação do livro Revolução na revolução, escrita pelo intelectual francês Régis Debray, em 1967, representou também uma importante contribuição sobre a experiência cubana. A partir das teses desenvolvidas por Che Guevara e Fidel Castro, Debray criou sua própria teoria revolucionária inspirada na Revolução Cubana, buscando disseminar a ideia de uma revolução continental e a principal tese guevarista: a teoria do foco. Para Debray, a experiência cubana é comumente compreendida de modo equivocado, o que acabaria por obliterar sua importância, já que:

\footnotetext{
${ }^{10}$ É válido ressaltar que após a Primeira (1960) e a Segunda Declaração de Havana (1962), ocorreu o crescimento de organizações guerrilheiras no continente como um todo.

${ }^{11}$ A Declaração final do evento apresentou 20 resoluções com destaque para: "1. Que constitui um direito e um dever dos povos da América Latina fazer a revolução (...); 2. Que o conteúdo essencial da revolução na América Latina está dado por seu enfrentamento ao imperialismo e às oligarquias de burgueses e latifundiários. Consequentemente, o caráter da revolução é o da luta pela independência nacional, para se emancipar das oligarquias, e o caminho socialista para seu pleno desenvolvimento (...); 4. Que a guerrilha - como embrião dos exércitos de libertação - constitui o método mais eficaz para iniciar e desenvolver a luta revolucionária na maioria de nossos países". "Declaração Final da Conferência da Organização LatinoAmericana de Solidariedade (OLAS)". BARÃO, Carlos Alberto, Op. cit, p. 270-1.
} 


\begin{abstract}
O impacto da revolução cubana tem sido vivido e pensado, principalmente na América Latina, através de formas e esquemas já catalogados pela história, entronizados, consagrados. Por isso, apesar de todo impacto que provocou, o golpe foi recebido amortecidamente. Hoje, passada a euforia, se começa a descobrir o sentido próprio de Cuba, o alcance de seu ensinamento, que antes havia escapado. Uma nova concepção de guerra de guerrilhas vem à luz (DEBRAY, 1967, p. 4)
\end{abstract}

Os caminhos percorridos por Debray para construir seu argumento apontam para uma década de grande efervescência na América Latina e no mundo. A opção pela radicalização política seria a grande chave para compreender os caminhos de determinados grupos naquele momento. Segundo ele, o processo aberto por Cuba era irreversível, na medida em que gerava um modelo para a América Latina, por meio do emprego de uma força móvel estratégica, núcleo do exército popular e do Estado socialista (BARÃO, 2003, p. 277). Tal como sistematizado por Guevara, o campo seria o grande palco da guerra de guerrilhas. Com as publicações de Che Guevara, dos discursos e escritos de Fidel Castro e os textos de Régis Debray, nascia na América Latina, segundo Jean Rodrigues Sales (2005, p. 46), uma nova corrente revolucionária: o castroguevarismo.

É importante ressaltar, contudo, que a centralidade da Revolução Cubana para a compreensão da constituição da identidade política dos grupos armados que surgirão na América Latina merece ser objeto de análise mais cuidadosa. O historiador Jean Rodrigues Sales (2005) chama atenção para o alinhamento das organizações comunistas brasileiras e os centros revolucionários internacionais, com destaque para URSS, China e Cuba. O argumento sustentado por Sales indica que a influência desses modelos é evidente, no entanto, esse fator por si só não explica os projetos políticos adotados pelas esquerdas revolucionárias, sobretudo nos anos 1960. O autor fez um mapeamento exaustivo do modo como o modelo cubano foi alvo de crítica e debate não apenas entre os grupos armados, mas inclusive entre o PC e PC do B. O resultado é uma análise que 
privilegia as contradições internas desses agrupamentos, ao mesmo tempo em que desmistifica a experiência cubana.

Esse ponto é importante porque, com alguma frequência, ao analisarmos o desenvolvimento teórico e prático da experiência cubana, o enfoque do castroguevarismo é privilegiado em detrimento de outras abordagens que também buscam compreender o que teria sido a Revolução Cubana e seus desdobramentos. ${ }^{12}$ Nesse sentido, em um momento no qual setores da esquerda se alinhavam, a seu modo, às teses defendidas por Castro, Guevara e Debray, intelectuais de diferentes correntes ideológicas se debruçaram sobre os acontecimentos em Cuba a partir da reinterpretação de alguns pressupostos que tinham definido até então as análises sobre o processo revolucionário cubano.

Em 1967, Vânia Bambirra, cientista política, militante da Polop e uma das fundadoras da vertente marxista da Teoria da Dependência, sistematizou sua primeira crítica à teoria do foco com a publicação do artigo Los errores de la teoria del foco. Em 1973, vivendo o exílio no Chile durante o governo da Unidade Popular, Bambirra trouxe à tona um estudo questionando de modo mais contundente os principais enfoques teóricos sobre a experiência cubana. Intitulado A revolução cubana: uma reinterpretação (BAMBIRRA, 1973), o objetivo da autora nesse livro é propor nova abordagem para o caso cubano ao pontuar a importância da resistência nos centros urbanos para o sucesso da luta revolucionária. Para Bambirra, a experiência cubana é equivocadamente analisada quando a centralidade recai no predomínio de apenas uma forma de luta, nesse caso, o foquismo. Além disso, coloca em evidência a existência de duas etapas no processo revolucionário: democrática e socialista, evidenciando a importância da fase democrática

\footnotetext{
${ }^{12} \mathrm{O}$ historiador Eric Hobsbawm também vai figurar como uma das vozes dissidentes à clássica narrativa da Revolução Cubana. Segundo ele, durante a década de 1960 foram poucas as produções realmente significativas sobre aquela experiência. HOBSBAWM, Eric. Viva la revolución: a era das utopias na América Latina. São Paulo: Companhia das Letras, 2017.
} 
que, segundo ela, é comumente negligenciada. Todas essas questões, na sua visão, acabaram por obliterar o papel histórico da pequena-burguesia nesse processo.

A experiência da Revolução Cubana, ainda que seu impacto encontre condições e características específicas em cada país, chamou atenção do governo norte-americano para a infiltração cada vez maior do ideário comunista na América Latina. De acordo com Arthur Schlesinger, historiador e assistente especial no governo de John F. Kennedy:

\begin{abstract}
A velha ordem na América Latina estava, evidentemente, em decomposição. Já não havia como preservar o status quo. A única questão, agora, era a forma que teria o futuro. Ali estava Fidel Castro, o líder apaixonado da Revolução Cubana, e, atrás dele também a força do comunismo vindo de fora do hemisfério; e ali estava o novo e jovem Presidente dos Estados Unidos, cuja subida ao poder já despertara novas esperanças nas Américas, tendo atrás de si as energias desiguais e descoordenadas de homens sensatos e da democracia latina nativa (...). Não obstante, se os Estados Unidos não estivessem prontos para oferecer um programa afirmativo de modernização democrática, novos Castros surgiriam, sem dúvida, pelo continente. Essa era a natureza da crise (SCHLESINGER, 1966, p.190).
\end{abstract}

No momento em que John F. Kennedy assumiu a presidência dos Estados Unidos, desafios de diversas ordens estavam postos para o seu mandato: guerras de descolonização nacional, o progressivo desgaste interno e externo causado pela Guerra do Vietnã, além da pedra no sapato, representada pela experiência cubana e sua defesa da luta armada como único modo possível de libertação dos países do Terceiro Mundo. Em seu famoso e emblemático discurso de posse, em 20 de Janeiro de 1961, Kennedy teria afirmado que estava disposto a "pagar qualquer preço, suportar qualquer encargo, enfrentar qualquer dificuldade, apoiar qualquer amigo, opor-se a qualquer inimigo, para assegurar a sobrevivência e o sucesso da liberdade". ${ }^{13} \mathrm{Na}$ defesa do chamado mundo livre, nenhum esforço deveria ser poupado. Em 3 de abril daquele mesmo ano, o Departamento

\footnotetext{
${ }^{13}$ Tradução nossa. Inaugural Address, Kennedy Draft, 01/17/1961; Papers of John F. Kennedy: President's Office Files, 01/20/1961-11/22/1963; John F. Kennedy Library; National Archives and Records Administration.
} 
de Estado dos Estados Unidos publicou um panfleto de 36 páginas intitulado "Cuba". Esse estudo sobre a situação na ilha e o futuro do continente não foi, nem de longe, escrito à revelia do presidente ou elaborado para ser compartilhado apenas entre os integrantes do alto escalão do governo. Houve, de fato, um esforço para sua distribuição maciça nos postos diplomáticos na América Latina e também na imprensa.

O conteúdo presente em "Cuba" é sofisticado justamente porque menciona a ideia de um "assalto do hemisfério e a transformação de Cuba em um satélite da União Soviética", conclama o povo cubano a romper os laços com o movimento comunista internacional com o objetivo de assegurar a dignidade da "Revolução Cubana original". Ou seja, a retórica construída informa que o problema não estava exatamente na derrubada do governo Batista e a instauração de um regime revolucionário, mas sim na traição de Fidel Castro aos ideais de liberdade, já que:

\begin{abstract}
Não está claro se Castro pretendia, desde o início, trair suas promessas de uma Cuba livre e democrática, entregar seu país ao bloco sino-soviético e montar um ataque ao sistema interamericano; ou se ele fez suas promessas originais com toda a sinceridade, mas, ao assumir suas novas responsabilidades, viu-se cada vez mais dependente de homens impiedosos a sua volta, com ideias claras e a organização disciplinada para levar essas ideias à prática. $\mathrm{O}$ importante não é o motivo, mas o resultado. O primeiro resultado foi a instauração de uma ditadura repressiva em Cuba. A existência de um regime dedicado a um ataque assim calculado às decências humanas seria por si só uma razão suficiente para uma preocupação intensa dentro do hemisfério. Nos últimos anos, a família americana das nações tem se movido firmemente na conclusão de que a segurança e o bem-estar de todas as repúblicas americanas serão melhor protegidas pelo estabelecimento e garantia dentro de cada república daquilo que a Carta da OEA chama de "direitos essenciais do homem" (...) Pois a liberdade é o destino comum do nosso hemisfério - liberdade da tirania doméstica e da intervenção estrangeira, da fome e da pobreza e do analfabetismo, liberdade para cada pessoa e nação nas Américas para realizar as grandes potencialidades da vida no século XX. ${ }^{14}$
\end{abstract}

A preocupação com o surgimento de novos Castros e novas Cubas estava na ordem do dia na agenda do novo presidente. O enfoque deveria estar no desenvolvimento

\footnotetext{
${ }^{14}$ Tradução nossa. Cuba: White Paper, Abril, 1961. Disponível em: https://jfklibrary.org/AssetViewer/Archives/AMSPP-WH06-009.aspx Acessado em: 14/05/2020.
} 
econômico, progresso social e democracia dos países periféricos, com especial atenção aos países latino-americanos (SCHLESINGER, 1966, p. 190). O resultado geral desse processo, essa batalha entre a liberdade e a tirania, foi um plano de ação com o objetivo de criar um novo programa de ajuda externa. Assim, em agosto de 1961, o Conselho Econômico e Social da OEA (Organização dos Estados Americanos), convocou os representantes de 22 países e Estados Unidos para uma reunião que teve lugar na cidade de Punta Del Este, Uruguai. O objetivo do encontro estava assentado na urgência de uma necessária união interamericana, com apoio do governo norte-americano.

Formulada nos marcos da Guerra Fria e da Revolução Cubana, a assinatura da Carta de Punta del Este lançava oficialmente a Aliança para o Progresso, um ousado programa de cooperação destinado ao desenvolvimento econômico e social da América Latina, além de ser pensada como um instrumento de luta contra o comunismo com recursos mais sofisticados que a simples repressão, em função de sua estreita eficácia (CANCELLI, 2017, p. 88). Não estamos querendo sugerir, no entanto, que as políticas repressivas e preventivas tenham sido abandonadas ou colocadas em segundo plano (AYERBE, 2004, p. 47). Inspirado no sucesso da derrubada do governo guatemalteco em 1954, e contando com financiamento da CIA, Kennedy tentou repetir a experiência em Cuba em 1961 por meio do treinamento militar de exilados cubanos com o objetivo de invadir a Baía dos Porcos, localizada ao sul da ilha. Como sabemos, a estratégia fracassou e logo veio à tona o papel do governo norte-americano naquela operação.

Kennedy sabia que estava diante de um desafio novo: na sua cruzada moral contra o comunismo, não era possível empregar os métodos de uma guerra convencional, disputada nos termos estritamente militares. Por isso mesmo, as estratégias de ingerência para lidar com focos de agitação social deveriam ser repensadas. Essa era uma guerra cuja dimensão psicossocial não deveria ser negligenciada. De acordo com sua visão, a insurgência era mais uma "batalha de corações e mentes" que de armas (SCHOULTZ, 2000: 393). Não à toa, Kennedy exigia que o Exército desenvolvesse "um novo tipo de estratégia; um tipo diferente de força e consequentemente um novo e diferente tipo de 
treinamento militar" (KAUFFMAN, 1968, p. 33) para enfrentar o que ele considerava ser a ameaça do dia.

Com efeito, a abordagem do novo presidente carregava consigo diferenças de estilo em relação ao seu predecessor, o republicano Dwight D. Eisenhower. Segundo João Roberto Martins Filho,
na política externa de Kennedy transparecem os princípios básicos da cultura da Guerra Fria. Tudo que se relacionava a Kennedy parecia novo: o "Grande Projeto" europeu, a "Nova África", a "Aliança para o Progresso", a "Resposta Flexível", a "Guerra Especial" ou a "Contra-Insurreição" (MARTINS FILHO, 1999, p. 67).

Nos últimos anos, assistimos à multiplicação das investigações sobre a Doutrina de Contrainsurgência como um dos pilares fundamentais da política externa do governo Kennedy (BLAUFARB, 1977; McCLINTOCK, 1992; SCHWAB, 1998; CASSIDY, 2008; ROSENAU, 2003). Esses trabalhos, via de regra, buscam enfatizar como o novo presidente se cercou de um importante staff intelectual e político, composto por universidades, agências, centros de formações de elites e think tanks, como o Centro de Estudos Internacionais, com recursos da Fundação Ford, ligado ao Massachusetts Institute of Technology (GILMAN, 2003, p. 158-9) e a Rand Corporation (LONG, 2006) em uma relação simbiótica entre conhecimento e poder.

Ainda que o estabelecimento de políticas para o enfrentamento de movimentos insurgentes não fosse exatamente uma novidade no mundo, a elaboração de um arcabouço teórico para enfrentar a subversão ultrapassou as fronteiras nacionais a partir de um intercâmbio de ideias, sobretudo com os franceses e sua expertise na luta contra a independência da Argélia. Segundo abordagem de Roger Trinquier, um dos principais teóricos da Doutrina de Contrainsurgência na França, "na moderna guerra de guerrilha, o inimigo é mais difícil de identificar” (TRINQUIER, 1961) justamente porque as fronteiras são mais ideológicas que físicas. Trinquier partia da premissa de que esse inimigo interno poderia estar em toda parte, de modo que o estabelecimento de uma rede de informações 
juntamente ao controle da sociedade seriam estratégias fundamentais nesse processo. David Galula, intelectual e oficial militar do exército francês, assim como Trinquier também teve papel central para o desenvolvimento da teoria e prática da Doutrina de Contrainsurgência nos Estados Unidos. Galula teve presença ativa no Centro de Estudos Internacionais da Universidade de Harvard, além de ter ministrado uma série de cursos em instituições de ensino militares naquele país (MARLOWE, 2010, p. 48-9).

Em setembro de 1961, Kennedy lançou o National Security Action Memorandum 88 (NSAM 88), em que discutia a importância da capacitação das forças militares dos países latino-americanos ${ }^{15}$ que deveriam atuar na luta contra o comunismo. Em setembro daquele mesmo ano, foi criada, sob coordenação do ex-agente da CIA e especialista em contrainsurgência, o general Edward G. Lansdale, a chamada Operation Mongoose. O objetivo era promover a derrubada do governo de Fidel Castro a partir de uma série de atividades clandestinas. No entanto, na avaliação de Lansdale, antes de qualquer intervenção militar, era necessário promover o caos interno em Cuba, de modo a incitar a insurreição e consequentemente diminuir o prestígio do governo cubano. O passo seguinte foi implementar o embargo econômico à Cuba. Segundo Luiz Moniz Bandeira:

\begin{abstract}
À guerra econômica conjugou-se a guerra psicológica, com o estabelecimento de 60 estações de rádio, em países da América Latina, e três na Flórida, destinadas à propaganda anticastrista e à difusão de rumores falsos, bem como de métodos para danificar instalações industriais e outros estabelecimentos do governo cubano. Estes atos de sabotagem e terrorismo recrudesceram nos meses de maio e junho, quando duas incursões paramilitares para destruir material bélico e incendiar canaviais ocorreram, apoiadas por aviões anfíbios, cujas bases estavam instaladas na Guatemala (BANDEIRA, 2012, p. 467)
\end{abstract}

\footnotetext{
${ }^{15}$ "Na escola de "guerra psicológica", sediada em Fort-Bragg, desde 1962 é ministrado aos latinoamericanos um curso de 18 horas "O comunismo e a propaganda comunista". São submetidos a uma doutrinação anticomunista particularmente intensa os representantes de todos os tipos de Forças Armadas dos países latino-americanos que fazem cursos ou passam por estágios nas 14 bases militares dos EUA na zona do canal do Panamá. O mais importante desses centros é o Centro de Instrução Militar dos EUA em Fort-Goolik, transformado em 1963 na Escola das Américas". KATCHATUROV, Karen Armenovitch. A expansão ideológica dos EUA na América Latina: doutrinas, formas e métodos da propaganda dos EUA. Rio de Janeiro: Civilização Brasileira, 1980, p. 221.
} 
Na esteira dessas ações, em janeiro de 1962, foi criado o Special Group on Counterinsurgency, que incluía o Departamento de Defesa, o Departamento de Estado e a CIA. A retórica adotada por Kennedy e seus brain trusts recuperava alguns programas do pós-guerra como o Point Four ${ }^{16} \mathrm{e}$ o Plano Marshall, aliado a um intenso esforço desenvolvimentista.

Tais esforços e ideais modernizantes, como já apontara Arthur Schlesinger, estavam assentados nos pressupostos da Teoria da Modernização, formulados no interior das Ciências Sociais nos Estados Unidos, e que forneceram importante subsídio teórico para o governo norte-americano, sobretudo nas décadas de 1950 e 1960, sobre como enfrentar os desafios dos países em desenvolvimento e seus movimentos revolucionários (LATHAM, 2000). A instabilidade econômica, política e social dos países subdesenvolvidos eram encaradas como um obstáculo para a necessária defesa do hemisfério no avanço das ideias comunistas na região. A transição para a modernização seria possível a partir da superação de sociedades tradicionais para sociedades modernas. Walt Rostow, conselheiro do governo Kennedy, em seu famoso livro, The Stages of Economic Growth: a non-comunist manifesto, publicado em 1960, afirma que o desenvolvimento econômico ocorre segundo um determinado conjunto de etapas. Nesse sentido, o papel da Contrainsurgência era justamente proteger o processo de desenvolvimento dos países cujas economias encontravam-se instáveis em função da infiltração comunista (ROSTOW, 1960). ${ }^{17}$

\footnotetext{
${ }^{16}$ De acordo com Martha Huggins: "Segundo a lógica do Ponto Quatro, se um país se tornasse economicamente autossuficiente, mediante assistência técnica de consultores anticomunistas, tornar-se-ia capaz de se proteger contra a subversão comunista (...). Em outras palavras, a 'ameaça' da Guerra Fria exigia novas medidas para proteger do comunismo a América Latina e outras regiões do mundo". HUGGINS, Martha. Polícia e política: relações Estados Unidos - América Latina. São Paulo: Cortez, 1998, p. 88 .

${ }_{17}$ Em 1968, o cientista político Samuel Huntington alertava para o fato de que o desenvolvimento econômico abrupto seria, na verdade, gerador de instabilidade e declínio da política. Para ele, os chamados países do Terceiro Mundo, em regiões como Ásia, África e América Latina, não amadureceram em termos de ordem pública e instituições políticas para ter uma democracia. Nesse sentido, o problema não seria a forma de governo, mas sim sua eficiência e a força, já que, segundo essa visão, a abertura de canais de participação política em países em desenvolvimento era considerado um risco. HUNTINGTON, Samuel. A
} 
Como é possível perceber, a Contrainsurgência foi uma batalha disputada, antes de mais nada, no plano das ideias, por meio da mobilização de narrativas, da conquista do apoio social e do mapeamento completo das fraquezas do inimigo a ser combatido. Por isso mesmo, esse tipo de ação foi exaustivamente estudada em todas as suas dimensões. O Departamento do Exército dos Estados Unidos (DEEU), por exemplo, foi mobilizado para a produção de manuais de combate à guerra de guerrilhas. Apesar desse tipo de publicação não representar uma novidade, ganhou uma inegável centralidade e importância pós-Revolução Cubana.

Em maio de 1961, o Exército publicou sua primeira análise sistematizada sobre como atuar nessa conjuntura. Denominado FM 31-15 - Operations Against Irregular Forces, elenca quatro medidas a serem tomadas com o objetivo de eliminar os dissidentes, além de prevenir o surgimento de novos movimentos guerrilheiros. Em primeiro lugar, destaca-se a necessidade de capacitação profissional com o objetivo de criar um sistema de inteligência realmente efetivo; em segundo lugar, o Exército deveria trabalhar com o objetivo de separar a população das influências internas e externas; em seguida, a guerrilha deveria ser destruída via força militar; por fim, o governo deveria elaborar estratégias de propaganda anticomunista com o objetivo de reconquistar a população civil. Nesse manual, e em outros ${ }^{18}$, temos a construção de uma retórica que trabalha constantemente com a noção do uso do terror como característica essencial dos grupos guerrilheiros por meio da descrição das táticas de guerrilha como a tomada de reféns (os casos envolvendo sequestros de representantes diplomáticos, por exemplo), assaltos a bancos, falsificação de documentos, etc:

Ordem Política nas Sociedades em Mudança. Rio de Janeiro: Forense Universitária; São Paulo: Ed. Universidade de São Paulo, 1975.

${ }^{18}$ Entre os manuais produzidos pelo Departamento do Exército, temos: Operations Against Irregular Forces, maio de 1961; Counterguerrilla Operations, maio de 1970; Counterinsurgency Operations, outubro de 2004; Counterinsurgency, dezembro de 2006; ArmySpecialOperations Forces UnconventionalWarfare, setembro de 2008; Tactics in Counterinsurgency, abril de 2009. 
[...] Terrorismo por assassinato, bombardeio, assalto à mão armada, tortura, mutilação e sequestro; provocação de incidentes, represálias e detenção de reféns; atividades de negação, tais como incêndio criminoso, inundação, demolição, usos de agentes químicos ou biológicos, ou outros atos destinados a impedir o uso de uma instalação, área, produto ou facilidade ("U.S. Department of the Army, Operations Against Irregular Forces, FM 31-15, Maio 1961, pp. 6-7).

O foco naquele momento era impulsionar a constituição de governos locais fortes, ao mesmo tempo em que havia a preocupação em eliminar a formação de possíveis focos guerrilheiros e a influência do movimento comunista internacional. A leitura desses manuais traz à tona o aprimoramento de uma lógica mais sofisticada para combater o terror, a partir do estudo de noções como preparação ideológica, estratégia, infiltração, inteligência, propaganda e controle. As revistas militares publicadas nos Estados Unidos, especialmente a Military Review, também foram fundamentais nessa tentativa de entender e lidar com a guerra não-convencional. Em muitos textos publicados, embora a questão do uso da força militar pelo governo norte-americano fosse enfatizada, havia a noção de que o sucesso da Contrainsurgência dependia do controle da sociedade civil em sua batalha contra os guerrilheiros. Essa ideia estava presente também em trabalhos produzidos por grupos ligados diretamente ao presidente dos EUA. Em agosto de 1962, um documento intitulado "Política de defesa interna no exterior dos EUA"19, produzido conjuntamente pelo Departamento de Estado, Departamento de Defesa e CIA, assinalava o seguinte:

A insurgência está fundamentada nas lealdades e atitudes do povo. Suas origens são domésticas e seu apoio deve continuar assim. As causas da insurgência, portanto, resultam das inadequações do governo local para retribuir ou remover insatisfações populares ou grupais. Os EUA devem sempre ter em mente que o alvo final e decisivo é o povo. A própria sociedade

\footnotetext{
${ }^{19}$ Esse documento foi incorporado ao National Security ActionMemorandum (NSAM) 182: CounterinsurgencyDoctrine, August, 24, 1962.
} 
está em guerra e os recursos, motivos e alvos da luta são encontrados quase totalmente dentro da população local. ${ }^{20}$

Todo esse aparato que foi mobilizado para lidar com a guerra de guerrilha que se alastrava pelos países do Terceiro Mundo buscava deixar clara a ideia de que o mundo livre, representado pelos Estados Unidos estava em risco. O discurso devidamente trabalhado informava que a Contrainsurgência era uma solução para um problema maior a ser enfrentado: o terror considerado intrínseco ao mundo comunista.

No caso específico da América Latina, é evidente que as ações e estratégias no âmbito do governo dos Estados Unidos, sobretudo após a posse de John F. Kennedy, para lidar com o impacto da Revolução Cubana e o surgimento e atuação de diversos grupos armados certamente não se encerram nessa análise. O que tentamos realizar foi explorar os projetos políticos articulados em torno dos desafios do mundo do pós-guerra, como o crescimento das guerras de libertação nacional em regiões como África e Ásia e a constituição de grupos armados, bem como a opção pela violência como prática política na América Latina. Por isso mesmo, o desenvolvimento da Doutrina de Contrainsurgência nos Estados Unidos funcionou como uma estratégia para enfrentar os movimentos guerrilheiros em diferentes partes do mundo e não apenas em Cuba. Para finalizar, é importante ressaltar, ainda, que se a experiência cubana foi decisiva para o estabelecimento de uma nova abordagem, não menos importante é reconhecer que o continente latino-americano já era alvo de atenção dos Estados Unidos antes de 1959.

\footnotetext{
${ }^{20}$ Tradução nossa. National Security Action Memoranda [NSAM]: NSAM 182, Counterinsurgency Doctrine. Disponível em: https://www.jfklibrary.org/Asset-Viewer/Archives/JFKNSF-338-010.aspx Acesso em: 14/09/2019.
} 


\section{Referências Bibliográficas}

\section{Fontes}

Cuba: White Paper, April1961

National Security Action Memorandum 88 (NSAM 88). Washington, September 5, 1961. U.S. DEPARTMENT OF STATE.FRUS, 1961-1963. vol. XII, American Republics. Washington, D.C., 1996.

National Security Action Memorandum (NSAM) 182: Counterinsurgency Doctrine, August, 24, 1962

U.S. Department of the Army, Operations Against Irregular Forces, FM 31-15, May 1961

U.S. Department of the Army, Civil Affairs Operations, FM 41-10, October 1969

U.S. Department of the Army, Counterguerrilla Operations, May 1970

U.S. Department of the Army, Counterinsurgency Operations, October 2004

U.S. Department of the Army, Counterinsurgency, December 2006

U.S. Department of the Army, Army Special Operations Forces Unconventional Warfare, September 2008

U.S. Department of the Army, Tactics in Counterinsurgency, April 2009

\section{Bibliografia}

ARENDT, Hannah. "Da Violência”. Crises da República. São Paulo: Perspectiva, 2010.

AYERBE, Luis Fernando. A Revolução Cubana. São Paulo: Editora Unesp, 2004.

AZEVEDO, Cecilia. "O sentido de missão no imaginário político norte-americano". Revista de História Regional 3(2), 77-90, 1998.

BAMBIRRA, Vânia. A revolução cubana: uma reinterpretação. Brasil: Ed. Centelha, 1973. 
BARÃO, Carlos Alberto. "A influência da Revolução Cubana sobre a esquerda brasileira nos anos 60”. In: MORAES, João Quartim de; REIS FILHO, Daniel Aarão (orgs). História do Marxismo no Brasil - Volume I: o impacto das revoluções. Campinas: Editora da Unicamp, 2003.

BOOTH, W. "Rethinking Latin America's Cold War". The Historical Journal, 2020, 123.

BLAUFARB, Douglas S. The Counterinsurgency Era: Doctrine and Performance, 1950 to the Present. New York: The Free Press, 1977.

CANCELLI, Elizabeth. O Brasil na guerra fria cultural: o pós-guerra em releitura.São Paulo: Intermeios, 2017.

CASSIDY, Robert M. Counterinsurgency and the Global War on Terror: Military Culture an Irregular War. Stanford University Press, 2008.

DEBRAY, Regis. Revolução na Revolução.Havana: Casa de lasAmericas, 1967

FANON, Frantz. Os condenados da terra. Juiz de Fora: Editora UFJF, 2005.

GALULA, David. Counterinsurgency Warfare: Theory and Practice.Praeger Security International. 1964.

GILMAN, Nils. Mandarins of the Future: Modernization Theory in Cold War America. Baltimore: John Hopkins University Press, 2003.

GOTT, Richard. Guerrilla movements in Latin America.Seagull Books, 2008.

GUEVARA, Che. A guerra de guerrilhas. São Paulo:Edições Populares, 1982.

GUEVARA, Ernesto Che. "Mensagem a Tricontinental", 1967. In: LOWY, Michael (org.). O marxismo na América Latina: uma antologia de 1909 aos dias atuais. São Paulo: Expressão Popular: Perseu Abramo, 2016.

HARMER, Tanya. "Two, Three, Many Revolutions? Cuba and the Prospects for Revolutionary Change in Latin America, 1967-1975". Journal of Latin American Studies 45, no.1 (2013): 61- 89

HOBSBAWM, Eric. Viva larevolución: a era das utopias na América Latina. São Paulo: Companhia das Letras, 2017. 
HUGGINS, Martha. Polícia e política: relações Estados Unidos - América Latina. São Paulo: Cortez, 1998.

HUNTINGTON, Samuel. A Ordem Política nas Sociedades em Mudança. Rio de Janeiro: Forense Universitária; São Paulo: Ed. Universidade de São Paulo, 1975.

JOSEPH, Gilbert M.; SPENSER, Daniela (orgs.). In from the Cold. Latin America's new encounter with the Cold War. Duke University Press, 2008.

JOSEPH, Gilbert. M. Border crossings and the remaking of Latin American Cold War Studies, Cold War History, 19:1, 141-170, 2019.

KATCHATUROV, Karen Armenovitch. A expansão ideológica dos EUA na América Latina: doutrinas, formas e métodos da propaganda dos EUA. Rio de Janeiro: Civilização Brasileira, 1980.

KAUFFMAN, Andrew. “On 'Wars of National Liberation'”. In: Military Review, n. 48, October 1968

LATHAM, Michael. Modernization as Ideology: American Social Science and "Nation Building” in the Kennedy Era. Chapel Hill: University of North Carolina Press, 2000.

LONG, Austin. On "other war": lessons from five decades of RAND counterinsurgency research. Santa Monica: Rand Corporation, 2006.

MARLOWE, Ann. David Galula: his life and intelectual context.Carlisle. Strategic Studies Institute, U.S. Army War College, 2010

MARTINS FILHO, João Roberto. "Os Estados Unidos, a Revolução Cubana e a contrainsurreição". Revista de Sociologia e Política da Universidade Federal do Paraná. Curitiba, n. 12, 1999.

McCLINTOCK, Michael. Instruments of Statecraft: U.S. Guerrilla Warfare, Counterinsurgency and Counterterrorism, 1940-1990. Pantheon Books, 1992.

MONIZ BANDEIRA, Luiz Alberto. De Martí a Fidel: a Revolução Cubana e a América Latina. Rio de Janeiro: Civilização Brasileira, 2012. 
MUNHOZ, Sidnei J. Imperialismo e Anti-Imperialismo, Comunismo e Anti-Comunismo durante a Guerra Fria. Revista Esboços, Florianópolis, v. 23, n. 36, p. 452-469, fev. 2017.

PORTANTIERO, Juan Carlos. "O marxismo latino-americano". In: HOBSBAWN et al. História do Marxismo.Rio de Janeiro: Paz e Terra, 1991.

PRASHAD, Vijay. The Darker Nations: a people's history of the Third World. The New Press, New York, 2007.

QUADRAT, Samantha Viz. A preparação dos agentes de informação e a ditadura civilmilitar no Brasil (1964-1985). Varia Historia, vol. 28, n. 47, pp. 19-41: jan/jun, 2012.

REGINATTO, Ana Carolina. “'O fim da primavera' no país da 'eterna tirania': o golpe de 1954 e a ruptura do projeto democrático na Guatemala". In: GRINBERG, Lucia; ARAÚJO, Maria Paula Nascimento; QUADRAT, Samantha Viz (orgs). 50 anos do golpe: debates discentes. Niterói: PPGH/UFF, 2016.

ROSENAU, William. "The Kennedy Administration, U.S. Foreign Internal Security Assistance and the Challenge of 'Subterranean War', 1961-1963”. Small Wars \& Insurgencies, Vol. 14, N. 3, 2003, pp. 65-99.

ROSTOW, Walt. The Stages of Economic Growth; a Non-Communist Manifesto.Cambridge University Press, 1960.

SALES, Jean Rodrigues. O impacto da Revolução Cubana sobre as organizações comunistas brasileiras (1959-1974).Tese (Doutorado em História) - Instituto de Filosofia e Ciências Humanas, Universidade Estadual de Campinas, 2005

SAUNDERS, Frances Stonor. Quem pagou a conta? A CIA na Guerra Fria da Cultura. São Paulo: Record, 2008.

SCHLESINGER, Arthur. Mil dias. John F. Kennedy na Casa Branca. Rio de Janeiro: Civilização Brasileira, 1966.

SCHOULTZ, Lars. Estados Unidos: poder e submissão. Uma história da politica norteamericana em relação à América Latina. Bauru/SP: EDUSC, 2000

SCHWAB, Orrin. Defending the Free World: John F. Kennedy, Lyndon Johnson and the Vietnam War, 1961-1965. Greenwood Publishing Group, 1998. 
SILVA, Izabel Priscila Pimentel da. "Por ti, América": Luta Armada, Internacionalismo e Latino-Americanismo na trajetória da Junta de Coordinación Revolucionaria.Tese de Doutorado. Niterói: UFF, 2016

TRINQUIER, Roger. Modern Warfare: a French view of counterinsurgency. Pall Mall Press, 1961.

VEGA, Louis Mercier. Guerrillas in Latin America: the technique of the Counter-State. Praeger, 1969.

VICK, Alan J; GRISSOM, Adam; ROSENAU, William; GRILL, Beth; MUELLER, Karl P. "The Challenge of Counterinsurgency: lessons from the Cold War and After". In: Air Power in the New Counterinsurgency Era.Rand Corporation, 2006.

WESTAD, Odd Arne. Reviewing the Cold War: Approaches, Interpretations, Theory. Frank Cass, 2000.

WESTAD, Odd Arne. The Global Cold War: Third World Interventions and the Making of Our Times. Cambridge University Press, 2007. 